\title{
Comparison between cryobiopsy and forceps biopsy in detection of epidermal growth factor receptor amplification in non-small-cell lung cancer
}

\author{
Ahmed S.H. Mohamed ${ }^{\mathrm{a}}$, Mohamed Hantera ${ }^{\mathrm{a}}$, Ragia S. Sharshar ${ }^{\mathrm{a}}$, \\ Amira Y. Abdelnaby ${ }^{\mathrm{b}}$, Ayman El Saka ${ }^{\mathrm{c}}$
}

\begin{abstract}
Background Non-small-cell lung cancer (NSCLC) represents $85 \%$ of lung cancer cases. Genotyping is now considered as a cornerstone in proper management and better results of such cancers, especially with targeted therapy. Cryobiopsy is a promising tool in NSCLC to obtain larger samples, with well-preserved tissue sufficient for accurate histopathological and gene detection.
\end{abstract}

Aim To compare cryobiopsy and ordinary forceps results in detection of epidermal growth factor receptor (EGFR) amplification in NSCLC.

\begin{abstract}
Materials and methods Samples from 34 patients with proven NSCLC by cryobiopsy versus forceps biopsy were compared for size, quality, and diagnostic yield of EGFR gene amplification.
\end{abstract}

Results The samples obtained by cryoprobe had larger size and better artifact-free areas with more diagnostic yield of EGFR gene amplification (29.4\%) versus with forceps biopsy $(8.8 \%)$, with gene amplification showing higher statistical significance in younger patients, never smokers, and women $(P<0.001)$.

\section{Introduction}

Lung cancer is the most common cancer worldwide, representing $13 \%$ of total cancers, with non-small-cell lung cancer (NSCLC) representing $\sim 85 \%$ of lung cancer cases [1].

In personalized medicine era, the advent of molecular biology has moved lung cancer histological classification beyond simple division into small cell lung cancer and NSCLC, making genotyping of NSCLCs a crucial aspect of management $[2,3]$.

Moreover, detection of specific genetic mutations has made targeted therapies more effective when these mutations are present. Tumors having somatic mutations in gene that encodes for tyrosine kinase domain of the cell surface protein, epidermal growth factor receptor (EGFR), were found to have better outcome to tyrosine kinase inhibitor (EGFR TKI) drugs, gefitinib and erlotinib [3].

Therefore, selecting adequate diagnostic biopsy tools to get reliable sufficient tissue biopsy with good quality, less risk, and discomfort for patient all are important for histologic characterization and mutation analysis, as a step for proper treatment and optimal targeted therapy in NSCLC [1].
Conclusion Cryobiopsy is an excellent tool for larger, betterquality sampling and for higher diagnostic yield of EGFR amplification in NSCLC.

Egypt J Bronchol 2019 13:636-643

(C) 2020 Egyptian Journal of Bronchology

Egyptian Journal of Bronchology 2019 13:636-643

Keywords: cryobiopsy epidermal growth factor receptor, cryobiopsy, EGFR, non-small-cell lung cancer

Departments of, ${ }^{\mathrm{a} C} \mathrm{C}$ est, ${ }^{\mathrm{b}} \mathrm{Clinical}$ Pathology, ${ }^{\mathrm{c} P a t h o l o g y}$, Faculty of Medicine, Tanta University, Tanta, Egypt

Correspondence to Ragia S. Sharshar, MD, Chest Department, Faculty of Medicine, Tanta University, Tanta, 1221, Egypt.

Tel \& fax: +20 122365 0568;

e-mail: ragia_sharshar@yahoo.com

resented-atECBIP congress 2017, poster oral discussion. Belgrade, Serbia. 28 April 2017

Received: 1 May 2019 Accepted: 20 May 2019

Published: 21 January 2020

The traditional diagnostic tool in lung cancer is through forceps biopsy via a flexible bronchoscope. One way to obtain larger tumor tissue sample is either by multiple biopsies or using cryobiopsies [4].

Flexible cryoprobe was first used for cryoablation as an alternative for mechanical debulking of malignant endobronchial stenosis, and because of larger size and less artifact-free tissue samples, the technique has been efficiently used for biopsy of endobronchial lesions [5-7].

This study aims to compare between cryobiopsy and ordinary forceps samples in detection of EGFR gene amplification by fluorescence in-situ hybridization technique (FISH).

\section{Materials and methods}

This prospective case study was done during the period from September 2015 to December 2016 on 50 patients recruited from Chest Department Tanta

This is an open access journal, and articles are distributed under the terms of the Creative Commons Attribution-NonCommercial-ShareAlike 4.0 License, which allows others to remix, tweak, and build upon the work non-commercially, as long as appropriate credit is given and the new creations are licensed under the identical terms. 
University Hospitals, but only 34 patients with endobronchial lesions were able to be sampled by three forceps biopsy attempts and one cryobiopsy from each patient, which were compared for size, quality of tissue, and complications of each type of biopsy. Moreover, the samples were compared for diagnostic yield of EGFR amplification.

\section{Inclusion criteria}

Adult patients with endobronchial lesion, previously pathologically confirmed as having NSCLC by clinical, radiological, and histological examination were included.

\section{Exclusion criteria}

Bleeding diathesis, anticoagulants use, oxygen saturation less than 90\%, hereditary diseases, congenital anomalies, severe comorbidity such as severe cardiac disease and other malignancy, and also any patient with contraindication(s) for flexible bronchoscopy as stated by British Thoracic Society guidelines in adults 2013were excluded from the study [8].

The study protocol was approved by the institutional ethics committee, and a written informed consent was taken from all patients before study.

Bronchoscopy and biopsy instruments used and obtained from were as follows: fiberoptic bronchoscopy (EB-1975k; Pentax, Tokyo, Japan), forceps biopsy (reusable fenestrated forceps FB-21C or FB-52C-1), and cryoprobe (Erbokryo; Erbe Elektromedizin GmbH, Tubingen, Germany).

Patients were first deeply sedated using intravenous midazolam and 10\% lidocaine spray intranasal and oropharyngeal, and $2 \%$ xylocaine solution within airways was used for local anesthesia. A cryoprobe was placed over endobronchial lesion and used for freezing for 3-5 s, and then the probe was pulled out en bloc with the bronchoscope. The sample on the probe's tip was thawed in sterile $0.9 \%$ sodium chloride water bath and placed in formalin [5,7].

\section{Histopathology}

Samples were fixed in 10\% formalin for $24 \mathrm{~h}$. Pathological analysis was performed. Biopsies were measured using centimeters, before sectioning for microscopic evaluation.

EGFR amplification method was as follows: detection of EGFR amplification was done using FISH technique, using Cytocell aquarius probe (cat. no.
LPS 003-SA/LPS 003-A), with probe specification EGFR, 7p11.2, Red, and D7Z1, 7p11.1-q11.1, Green [9].

\section{Sample preparation}

Formalin-fixed paraffin-embedded tissue sections were prepared according to laboratory or institution guidelines. For FISH, 4-6- $\mu$ m-thick formalin-fixed paraffin-embedded tissue sections were cut.

\section{Tissue sample pretreatment}

For pretreatment, Aquarius tissue pretreatment kit (LPS 100) was used.

\section{Pre-denaturation steps}

Probe was removed from the freezer and allowed to warm to room temperature.

\section{Denaturation of specimen DNA and probe hybridization}

Overall, 10-15 $\mu$ l of probe sample was added to a target area, and then covered and sealed with (FixoGum) rubber cement. The slide was placed on the hybrid surface (Vysis, Vysis hybrite CA 92641, California, USA). The hybrid was heated to $80^{\circ} \mathrm{C}$ for $10 \mathrm{~min}$ (for denaturation) and then cooled to $37^{\circ} \mathrm{C}$ overnight for hybridization.

\section{Post-hybridization washes}

The coverslip and traces of glue were removed carefully and then the slide was immersed in $0.4 \times \mathrm{SSC}$ with $\mathrm{NP} 40(\mathrm{pH} 7.0)$ at $74^{\circ} \mathrm{C}$ for $2 \mathrm{~min}$, and the slide then transferred to $2 \times \mathrm{SSC}$ with NP40 at RT ( $\mathrm{pH} 7.0$ ) for 2 min. Overall, $10-15 \mu 1$ of DAPI was applied onto each sample and covered with a coverslip, and the slide was placed in a dark box in a fridge for $20-30 \mathrm{~min}$ before screening.

\section{Interpretation of result and image capture}

Slides were examined with an epifluorescence Olympus, BX60 microscope (New York, USA). The images were captured with scan IAI camera fitted with PC Applied Image System (Pittsburgh, USA) analysis software. Only interphases with clear signals, with no overlapping or splitting, were analyzed [9].

\section{Statistical analysis}

Statistical analysis was done using SPSS version 20 (SPSS Inc., Chicago, Illinois, USA). Continuous data were expressed as mean $\pm \mathrm{SD}$ and categorical variables as percentages. Multivariant correlation was used for correlation, $P$ value was considered significant if less than 0.05 . 


\section{Results}

From 50 patients who attended the Chest Department of Tanta University Hospitals, 16 patients tissue specimens were not of good quality for FISH analysis and no signals could be detected for interpretation. Therefore, 34 patients were enrolled in the study, comprising 14 males and 20 females, with mean age of $57.44 \pm 5.12$ years. The study population data are illustrated in Table 1.

On comparing the samples taken by forceps biopsy and cryobiopsy, cryoprobe samples were of better quality with larger size and artifact-free areas. The median size of the cryoprobe and forceps biopsies was $1.51 \pm 0.41$ and $0.89 \pm 0.31 \mathrm{~cm}$, respectively, whereas cryobiopsies artifact-free tissue was significantly larger $(1.45 \pm 0.43$ vs. $0.58 \pm 0.22 \mathrm{~cm}, P<0.001$; Tables 2 and 3 and Figs 1 and 2).

\section{Table 1 Basic demographic data of patients in both groups}

\begin{tabular}{lc}
\hline & Frequency (\%) \\
\hline Age (mean $\pm S D)$ & $57.44 \pm 5.12$ \\
Sex & \\
Male & $14(41.2)$ \\
Female & $20(58.8)$ \\
Smoking & \\
Smoker & $12(35.3)$ \\
Ex-smoker & $5(14.7)$ \\
Nonsmoker & $17(50)$ \\
Tumor size (cm) & \\
$>3$ & $20(58.8)$ \\
$<3$ & $14(41.2)$ \\
Tumor site & \\
Right main & $7(20.6)$ \\
Left main & $44(11.8)$ \\
RLL & $10(29.4)$ \\
RUL & $12(2.9)$ \\
LLL & $12(35.3)$ \\
Pathology & $20(58.8)$ \\
Adenocarcinoma & \\
Sq C C & \\
\hline
\end{tabular}

LLL, left lower lobe; RLL, right lower lobe; RUL, right upper lobe; Sq C C, squamous cell carcinoma.
On comparing the complications of procedure in both groups, no reported cases of pneumothorax or respiratory failure was seen. There was only mild bleeding (i.e. treated with suctioning and cold saline) in 11 (32.4\%) of 34 cases in cryobiopsy group compared with nine $(26.5 \%)$ of 34 cases in forceps biopsy group, with no statistically significant difference between the two groups.

\section{Figure 1}

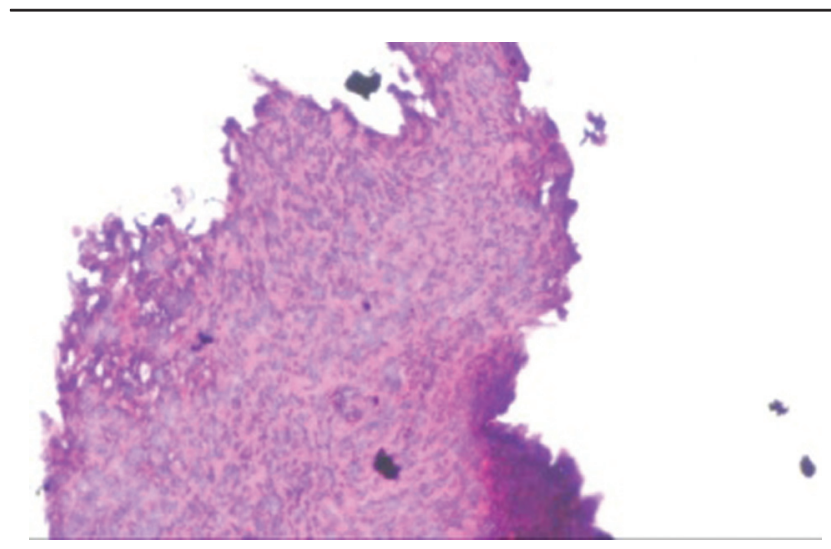

A case of non-small-cell lung cancer (H\&E 400) by forceps with crash artifact.

\section{Figure 2}

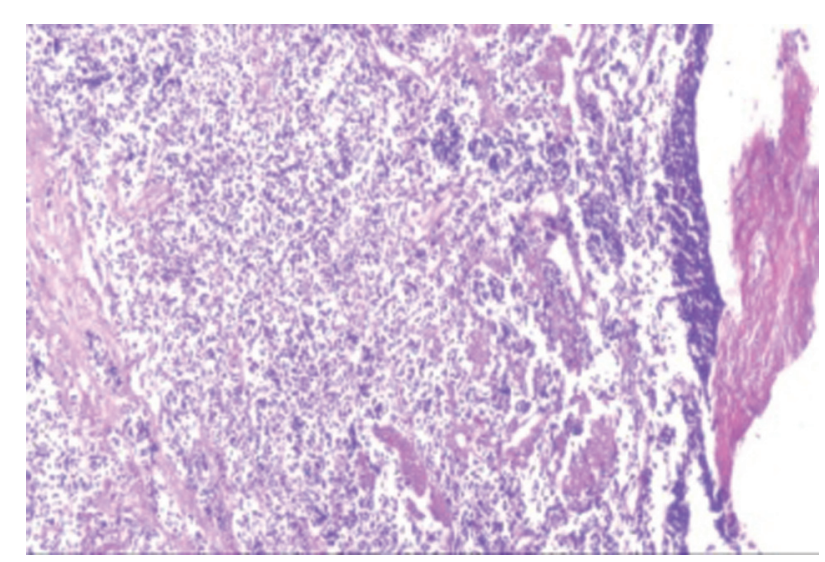

A case of non-small-cell lung cancer (H\&E 400) by cryobiopsy with no crash artifact.

Table 2 Size of sample of cryobiopsy versus forceps biopsy

\begin{tabular}{llllll}
\hline & \multicolumn{2}{c}{ Cryobiopsy } & & \multicolumn{2}{c}{ Forceps biopsy } \\
\cline { 2 - 3 } & Range & Mean \pm SD & & Range & Mean \pm SD \\
\hline Size of sample & $0.7-2.2$ & $1.51 \pm 0.41$ & $0.2-1.4$ & $0.89 \pm 0.31$ \\
\hline
\end{tabular}

Table 3 Artifact-free tissue areas of cryobiopsy versus forceps biopsy

\begin{tabular}{llllll}
\hline & \multicolumn{2}{c}{ Cryobiopsy } & & \multicolumn{2}{c}{ Forceps biopsy } \\
\cline { 2 - 3 } & Range & Mean \pm SD & & Range & Mean \pm SD \\
\hline Artefact free area & $0.8-2.1$ & $1.45 \pm 0.43$ & $0.2-0.9$ & $0.58 \pm 0.22$ & $<0.001$ \\
\hline
\end{tabular}


EGFR gene status was classified into six categories based on tumor cells frequency with specific gene copy numbers and chromosome seven centromere. These categories were further classified into (a) FISH negative (disomy, low trisomy, high trisomy, and low polysomy) and (b) FISH positive (high polysomy and gene amplification) $[10,11]$.

As for diagnostic yield of EGFR amplification (gene copy number), FISH positivity (amplification and high polysomy) was detected by bronchoscopic cryobiopsy in $10(29.4 \%)$ of 34 patients whereas forceps biopsy showed FISH positivity in only three $(8.8 \%)$ cases $(P<0.001$; Table 4 and Figs 3 and 4$)$.

Samples taken with cryobiopsy that showed FISH positivity were three (8.8\%) cases with EGFR amplification, and seven (20.5\%) cases with high polysomy (Fig. 5).

There was a correlation between EGFR and tumor histopathological type, smoking status, and sex. Of the 10 cases of EGFR amplification using FISH technique detected with cryobiopsy, there were seven cases of adenocarcinoma and three cases of squamous cell carcinoma (Fig. 6). However, in the samples taken by forceps biopsy. Of the three cases of EGFR gene amplification, there were two cases of adenocarcinoma and one case of squamous cell carcinoma. There was a positive correlation between adenocarcinoma histopathological type, smoking status, and sex, so EGFR gene amplification was predominant in females, and nonsmokers with adenocarcinoma (Table 5).

\section{Discussion}

Advances in molecular biology are improving our understanding of lung cancer and changing approach to treatment. International Association for the Study of Lung Cancer/American Thoracic Society/European Respiratory Society guideline recommends mutational testing in nonsquamous NSCLC $[2,12,13]$.

In general, the larger the biopsy sample the more accurate the diagnosis. However, increasing biopsy

Table 4 Diagnostic yield of epidermal growth factor receptor gene copy number by fluorescence in-situ hybridization analysis in cryobiopsy versus forceps biopsy

\begin{tabular}{lccc}
\hline & Cryobiopsy $[N(\%)]$ & Forceps biopsy $[N(\%)]$ & $P$ value \\
\hline Fluorescence in-situ hybridization positive & $10(29.4)$ & $3(8.8)$ & $0.031^{*}$ \\
Fluorescence in-situ hybridization negative & $24(70.6)$ & $31(91.2)$ & \\
\hline
\end{tabular}

${ }^{*} P \leq 0.05$, statistically significant.

Figure 3
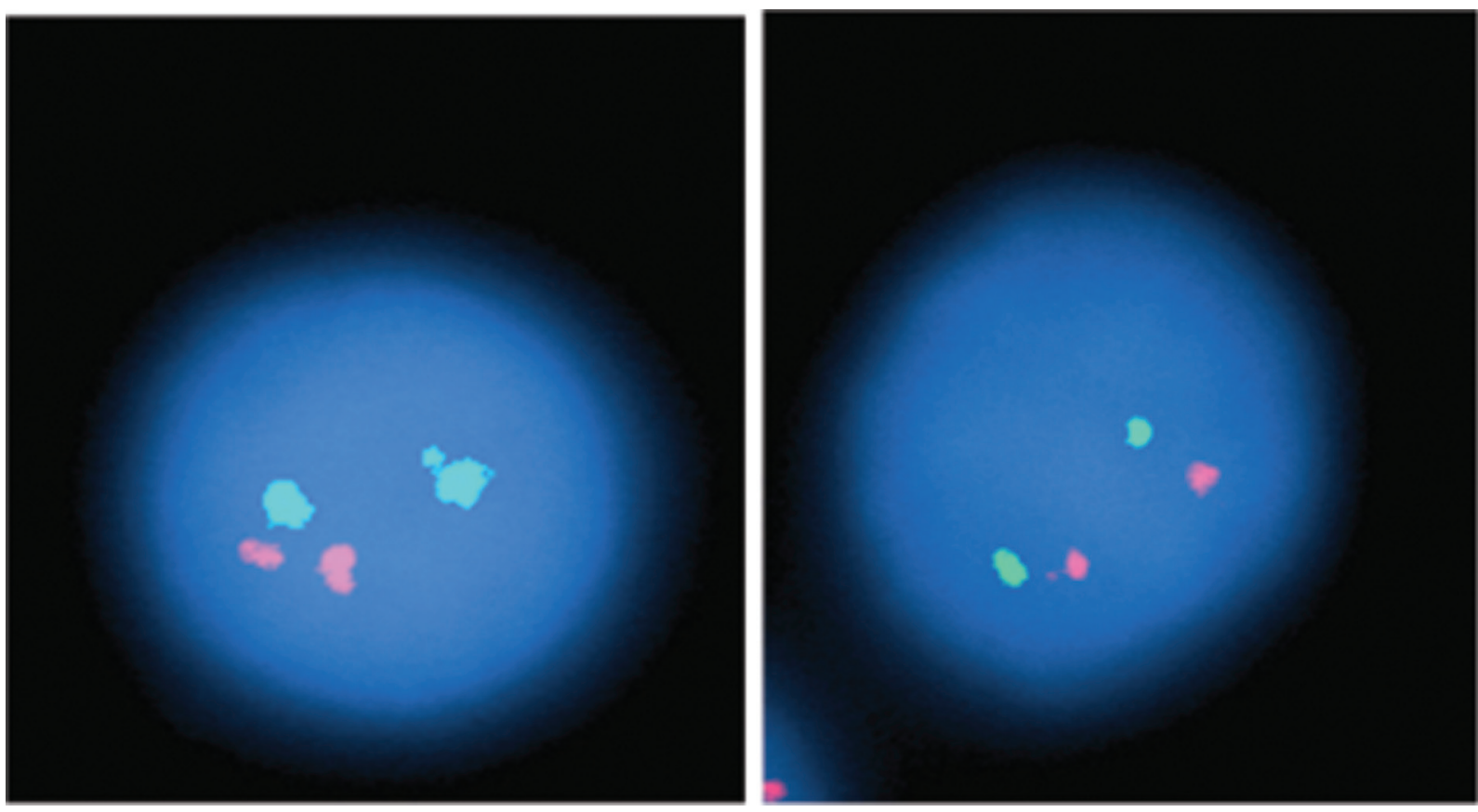

A case of non-small-cell lung cancer show interphase cell with normal epidermal growth factor receptor gene gain (two orange signals and two green signals). 
Figure 4
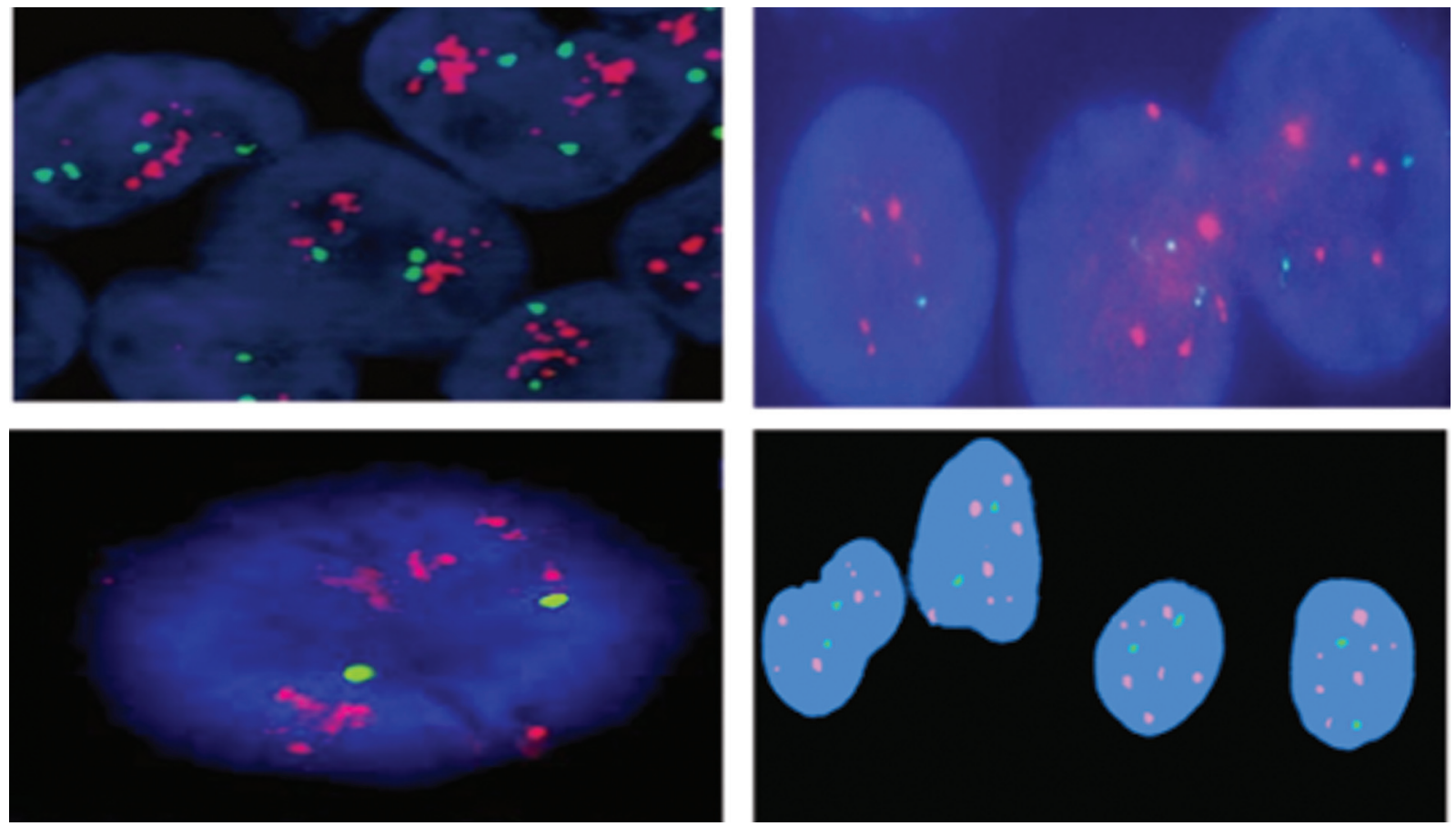

A cases of non-small-cell lung cancer show interphase cell with epidermal growth factor receptor gene amplification (multiple orange signals).

Figure 5

\section{EGFR gene copy number}

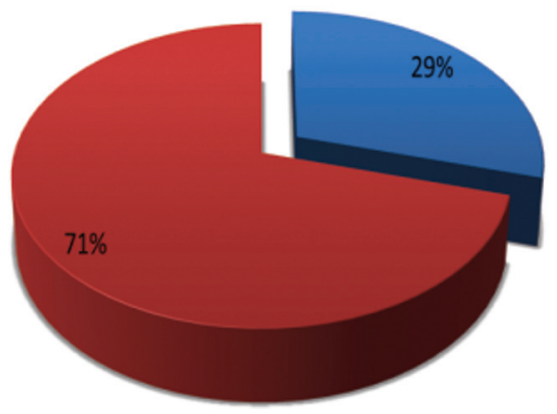

FISH positive

- FISH negative

Epidermal growth factor receptor gene copy number by fluorescence in-situ hybridization analysis of studied cases.
Figure 6

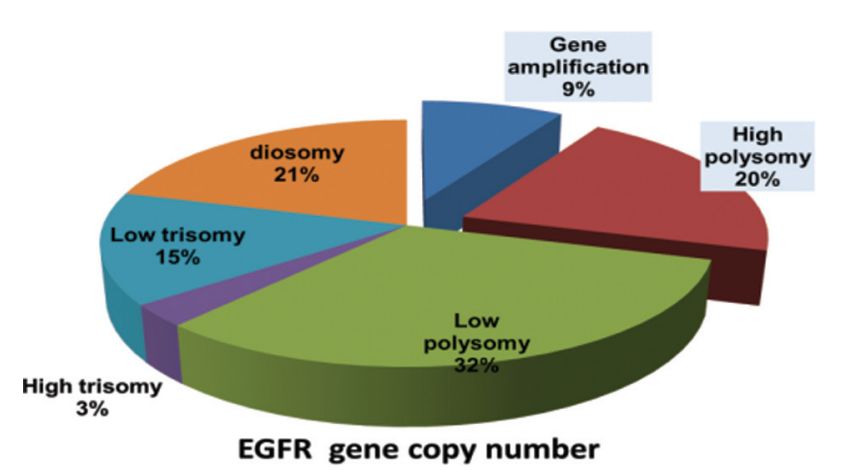

Categories of epidermal growth factor receptor gene copy number of studied cases.

Table 5 Multivariant analysis of correlation between epidermal growth factor receptor gene amplification and different characteristic of studied cases

\begin{tabular}{|c|c|c|c|}
\hline & \multicolumn{2}{|c|}{ Multivariate } & \multirow[t]{2}{*}{$P$ value } \\
\hline & Odds ratio & $95 \%$ confidence interval & \\
\hline Pathology (adenocarcinoma) & 0.452 & $0.236-0.857$ & $0.025^{*}$ \\
\hline Smoking (nonsmoker) & 0.294 & $0.033-0.416$ & $0.019^{*}$ \\
\hline Sex (female) & 0.536 & $0.364-0.842$ & $0.043^{*}$ \\
\hline Age & 0.657 & $0.208-2.365$ & 0.321 \\
\hline Size & 0.854 & $0.415-3.652$ & 0.256 \\
\hline Site & 0.698 & $0.306-2.067$ & 0.218 \\
\hline
\end{tabular}

${ }^{*} P \leq 0.05$, statistically significant.

size also increases the risk of complications. Even on obtaining multiple specimens, these may be not enough to perform more detailed molecular analysis. So biopsy tool of choice should be safe and able to get large 
biopsies without sample morphologic changes, thereby reducing the number of additional sampling and repeated bronchoscopies $[1,4,14]$.

An inexpensive method for increasing biopsy yield is flexible cryobiopsy, which has most of these advantages. Cryobiopsy of endobronchial lesions has better diagnosis and less complications and operating time. Cryoprobe also facilitates sampling of tangentially positioned lesions to bronchoscope, which are difficult to sample with ordinary forceps [4,15-17].

Regarding the histological quality of cryobiopsies, in our study, we founded that tissue samples obtained by cryoprobe had larger size and better artifact-free areas compared with forceps biopsies $(P<0.001)$. Our results were in accordance with our previous work that demonstrated cryotechnique gives both larger and also better quality specimens with less mechanical damage [5].

The same results were proved in many studies, such as Hetzel and colleagues, who stated that artifact-free area and molecular markers were well-preserved in cryobiopsies, enabling better immunohistochemical diagnostics whereas forceps biopsies exhibit crush artifacts, making diagnosis difficult, especially in small biopsy samples. Moreover, Schumann and colleagues showed the same advantage for cryobiopsy over forceps biopsy, with larger and qualitatively better quality specimens. Another study showed the mean volumes of sample by cryobiopsy significantly provided high diagnostic accuracy, in addition to sampling both exophytic and flat lesions. Other authors also described the total area of cryobiopsies samples was twice larger than forceps biopsies [4,7,18-21].

This may be explained by three factors: first, cryoprobe only touches the tissue, with no grasping of the sampled tissue, whereas forceps biopsy needs lesion squeezing; second, it applies cold effect at the probe's tip creating hemostasis, which results in artifact-free area, and also more freezing time increases size of sample, whereas forceps biopsies are limited by forceps claws size; and third, specimens are released in fresh frozen condition $[7,22,23]$.

Regarding complications of cryobiopsy, as cartilage tissue is insensitive to freezing, the only complication is bleeding. Bleeding risk significantly increases with extra biopsies. A cooling time of $3 \mathrm{~s}$ is enough to gather a diagnostic sample without bleeding risk [24].
In our study, only mild bleeding occurred and was not statistically significant different between the two groups. This may be explained by vasoconstrictory effect and short bleeding duration, despite the larger defects created at the site of tissue sampling. Our results were in accordance with many previous studies. Most of these studies showed risk of bleeding was same with cryobiopsy and conventional methods ranging from 5,6-18, 10 up to $28 \%$ as reported by Schumann and colleagues, Segmen and colleagues, Jabari and colleagues, and Eldahdouh and colleagues, respectively. On the contrary, only Hetzel and colleagues, showed mild bleeding (no intervention need for control) was significantly higher in cryobiopsy, but more severe bleeding was similar in both techniques $[4,7,24-26]$.

EGFR is a cell surface tyrosine kinase receptor much expressed on both epithelial and stromal cells. EGFR overexpression occurs in many solid tumors, including NSCLC, with a prognostic value and correlation to disease progression and survival $[27,28]$.

Our study showed that cryoiopsy was a safe method, with a better diagnostic yield (29.4\%) compared with $8.8 \%$ forceps biopsy for determination of EGFR copy number.

FISH positivity of $29.4 \%$ in our study was in accordance with previous studies that reported high EGFR gene amplification in $7-45 \%$ of lung cancer. This wide range may be owing to variable methods and positivity criteria [8,29-32], but on adopting the same criteria in previous studies similar to our study, values ranged from 31 to $48 \%$ [8,33-35].

In agreement with our results, but with much higher results, was the study by Lee and colleagues regarding EGFR FISH positivity, as represented in $45 \%$ of patients with NSCLC, and also Pinter and colleagues concluded that EGFR gene copy number was increased in $40 \%$ of 118 patients. Unlike our study, Zhang and colleagues reported FISH was positive in $62 \%$ of cases [36-38].

We analyzed EGFR in relation to age and sex and revealed that amplification can be presented with lung cancer in younger patients and never smokers and in women more than men; these differences were statistically significant. These findings were in accordance with a previous work by Zhang et al. [38] who showed gene amplification was related to mutation, primarily occurring in females, nonsmokers, and patients with adenocarinomas (all $P<0.001$ ). 
On the contrary, Gaber et al. [28] founded FISH positivity was more in adencarcinoma than squamous cell carcinoma but was not statistical significance and was not associated with age, sex, smoking, or tumor size. Other study by Sone et al. [34] observed FISH-positive results in adenocarcinomas and nonsmokers, not associated with sex, but were not statistically significant.

\section{Conclusion}

Bronchoscopic cryobiopsy might provide samples with better material than forceps biopsy allowing better diagnostic yield in detection of EGFR gene amplification.

\section{Financial support and sponsorship \\ Nil.}

\section{Conflicts of interest}

There are no conflicts of interest.

\section{References}

1 Slavik T, Asselah F, Fakhruddin N. Diagnosis and predictive molecular analysis of non-small-cell lung cancer in the Africa-Middle East region: challenges and strategies for improvement. Clin Lung Cancer 2014; 15:398-404.

2 Ofiara LM, Navasakulpong A, Ezer N, Gonzalez AV. The importance of a satisfactory biopsy for the diagnosis of lung cancer in the era of personalized treatment. Curr Oncol 2012; 19:S16-S23.

3 Jeyabalan A, Bhatt N, Plummeridge MJ, Medford RL. Adequacy of endobronchial ultrasound-guided transbronchial needle aspiration samples processed as histopathological samples for genetic mutation analysis in lung adenocarcinoma. Mol Clin Oncol 2016; 4:119-125.

4 Hetzel J, Eberhardt R, Herth FJ, Petermann C, Reichle G, Freitag L, et al. Cryobiopsy increases the diagnostic yield of endobronchial biopsy: a multicenter trial. Eur Respir J 2012; 39:685-690.

5 Mohamed AS, Sharshar RS, Wasfy RE. The diagnostic yield of cryobiopsy versus forceps biopsy of malignant endobronchial lesions. Egypt $J$ Chest Dis Tuberc 2015; 65:267-270.

6 Hetzel M, Hetzel J, Schumann C, Marx N, Babiak A. Cryorecanalization: a new approach for immediate management of acute airway obstruction. $J$ Thorac Cardiovasc Surg 2004; 127:1427-1431.

7 Schumann C, Hetzel J, Babiak AJ, Merk T, Wibmer T, Moller P, et al. Cryoprobe biopsy increases the diagnostic yield in endobronchial tumor lesions. J Thorac Cardiovasc Surg 2010; 140:417-421.

8 Du Rand IA, Blaikley J, Booton R, Chaudhuri N, Gupta V, Khalid S, et al. British Thoracic Society guideline for diagnostic flexible bronchoscopy in adults: accredited by NICE. Thorax 2013; 68:i1-i44.

9 Werner M, Wilkens L, Aubele M, Nolte M, Zitzelsberger H, Komminoth P. Interphase cytogenetics in pathology: principles, methods, and applications of fluorescence in situ hybridization (FISH). Histochem Cell Biol 1997; 108:381-390.

10 Cappuzzo F, Hirsch FR, Rossi E, Bartolini S, Ceresoli GL, Bemis L, et al. Epidermal growth factor receptor gene and protein and gefitinib sensitivity in non-small-cell lung cancer. J Natl Cancer Inst 2005; 97:643-655.

11 Varella-Garcia M, Diebold J, Eberhard DA, Geenen K, Hirschmann A, Kockx $M$, et al. EGFR fluorescence in situ hybridisation assay: guidelines for application to non-small-cell lung cancer. J Clin Pathol 2009; 62:970-977.

12 Mazzone P, Jain P, Arroliga AC, Matthay RA. Bronchoscopy and needle biopsy techniques for diagnosis and staging of lung cancer. Clin Chest Med 2002; 23:137-158.
13 Travis WD, Brambilla E, Noguchi M, Nicholson AG, Geisinger K, Yatabe Y, et al. Diagnosis of lung cancer in small biopsies and cytology: implications of the 2011 International Association for the Study of Lung Cancer/ American Thoracic Society/European Respiratory Society classification. Arch Pathol Lab Med 2013; 137:668-684.

14 Thunnissen E, Kerr KM, Herth FJ, Lantuejoul S, Papotti M, Rintoul RC, et al. The challenge of NSCLC diagnosis and predictive analysis on small samples.Practical approach of a working group. Lung Cancer 2012; 76:1-18.

15 Aktas Z, Gunay E, Hoca NT, Yilmaz A, Demirag F, Gunay S, et al. Endobronchial cryobiopsy or forceps biopsy for lung cancer diagnosis. Ann Thorac Med 2010; 5:242-246.

16 Hetzel J, Hetzel M, Hasel C, Moeller P, Babiak A. Old meets modern: the use of traditional cryoprobes in the age of molecular biology. Respiration 2008; 76:193-197.

17 Chou CL, Wang CW, Lin SM, Fang YF, Yu CT, Chen HC, et al. Role of flexible bronchoscopic cryotechnology in diagnosing endobronchial masses. Ann Thorac Surg 2013; 95:982-986.

18 Rubio ER, Le SR, Whatley RE, Boyd MB. Cryobiopsy: should this be used in place of endobronchial forceps biopsies? Biomed Res Int 2013; 2013:730574.

19 Nicholson AG, Gonzalez D, Shah P, Pynegar MJ, Deshmukh M, Rice $A$, et al. Refining diagnosis and EGFR status of NSCLC in biopsy and cytologic material, using panel of mucin staining, TTF-1, cytokeratin 5/ 6, P63, and EGFR mutation analysis. J Thorac Oncol 2010; 5:436-441.

20 Tiseo M, Rossi G, Capelletti M, Sartori G, Spiritelli E, Marchioni A, et al. Predictors gefitinib outcomes in advanced non-small cell lung cancer (NSCLC): study of comprehensive panel of molecular markers. Lung Cancer 2010; 67:355-360.

21 Ehab A, El-Badrawy MK, Moawad AA, Abo-Shehata ME. Cryobiopsy versus forceps biopsy in endobronchial lesions, diagnostic yield and safety. Adv Respir Med 2017; 85:301-306.

22 Babiak A, Hetzel J, Krishna G, Fritz P, Moeller P, Balli T, et al. Transbronchial cryobiopsy: a new tool for lung biopsies. Respiration 2009; 78:203-208.

23 Franke KJ, Szyrach M, Nilius G, Hetzel J, Hetzel M, Ruehle KH. Experimental study on biopsy sampling using new flexible cryoprobes: influence of activation time, probe size, tissue consistency, and contact pressure of probe on size of biopsy specimen. Lung 2009; 187:253-259.

24 Segmen F, Aktas Z, Özturk A, Kizilgöz D, Yilmaz A, Alici IO. How many samples would be optimal for endobronchial cryobiopsy? Surg Endosc 2017; 31:1219-1224.

25 Jabari H, Sami R, Fakhri M, Kiani A. Different protocols for cryobiopsy versus forceps biopsy in diagnosis of patients with endobronchial tumors. Pneumologia 2012; 61:230-233.

26 El-Dahdouh S, AbdElaal G, El-kady N. Comparison between endobronchial forceps-biopsy and cryo-biopsy by flexible bronchoscopy. Egypt J Chest Dis Tuberc 2015; 65:325-331.

27 Nicholson RI, Gee JM, Harper ME. EGFR and cancer prognosis. Eur J Cancer 2001; 37:S9-S15.

28 Gaber R, Watermann I, Kugler C, Reinmuth N, Huber RM, Schnabel PA, et al. Correlation of EGFR expression, gene copy number and clinicopathological status in NSCLC. Diagn Pathol 2014; 9:165.

29 Hirsch FR, Varella-Garcia M, McCoy J, West H, Xavier AC, Gumerlock P, et al. Increased EGFR gene copy number detected by fluorescence in situ hybridization is associated with increased sensitivity to gefitinib in patients with bronchioloalveolar carcinoma subtypes.A Southwest Oncology Group study. J Clin Oncol 2005; 23:6838-6845.

30 Takano T, Ohe Y, Sakamoto H, Tsuta K, Matsuno Y, Tateishi U, et al. Epidermal growth factor receptor gene mutations and increased gene copy numbers predict gefitinib sensitivity in patients with recurrent non-smallcell lung cancer. J Clin Oncol 2005; 23:6829-6837.

31 Dacic S, Flanagan M, Cieply K, Ramalingam S, Luketich J, Belani C, et al. Significance of EGFR protein expression and gene amplification in NSCLC. Am J Clin Pathol 2006; 125:860-865.

32 Bell DW, Lynch TJ, Haserlat SM, Harris PL, Okimoto RA, Brannigan BW, et al. Epidermal growth factor receptor mutations and gene amplification in non-small-cell lung cancer: molecular analysis of the IDEAL/INTACT gefitinib trials. J Clin Oncol 2005; 23:8081-8092.

33 Hirsch FR, Varella-Garcia M, Bunn PAJr, Franklin WA, Dziadziuszko R, Thatcher $\mathrm{N}$, et al. Molecular predictors of outcome with gefitinib in a phase III placebo-controlled study in advanced non-small-cell lung cancer. J Clin Oncol 2006; 24:5034-5042. 
34 Sone T, Kasahara K, Kimura H, Nishio K, Mizuguchi M, Nakatsumi Y, et al. Comparative analysis of epidermal growth factor receptor mutations and gene amplification as predictors of gefitinib efficacy in Japanese patients with non-small-cell lung cancer. Cancer 2007; 109:1836-1844.

35 Ichihara S, Toyooka S, Fujiwara Y, Hotta K, Shigematsu H, Tokumo M, et al. The impact of epidermal growth factor receptor gene status on gefitinib-treated Japanese patients with non-small-cell lung cancer. Int $J$ Cancer 2007; 120:1239-1247.

36 Lee HJ, Xu X, Choe G, Chung DH, Seo JW, Lee JH, et al. Protein overexpression and gene amplification of epidermal growth factor receptor in NSCLC: comparison of four commercially available antibodies by immunohistochemistry and fluorescence in situ hybridization study. Lung Cancer 2010; 68:375-382.

37 Pinter F, Papay J, Almasi A, Sapi Z, Szabo E, Kanya M, et al. Epidermal growth factor receptor high gene copy number and activating mutations in lung adenocarcinomas are not consistently accompanied by positivity for EGFR protein by standard immunohistochemistry. J Mol Diagn 2008; 10:160-168.

38 Zhang L, Cai L, Li Z, Wang W, Guo K, Shao J, et al. Relationship between EGFR gene mutation and copy number in Chinese patients with NSCLC.EGFR gene status in NSCLC. Chin J Cancer 2012; 31:491-499. 